\title{
Risk assessment of hot and humid environments through an integrated fuzzy AHP-VIKOR method
}

\author{
Bahman Ramavandi ${ }^{1} \cdot$ Amir Hossein Darabi ${ }^{2} \cdot$ Mohsen Omidvar $^{3}$
}

Accepted: 11 February 2021

(C) The Author(s), under exclusive licence to Springer-Verlag GmbH, DE part of Springer Nature 2021

\begin{abstract}
Working in hot and humid environments can jeopardize the health and safety of the workers and reduce their efficiency. Different physical, environmental, and human factors can influence the risk level of working in these atmospheres. Therefore, the risk assessment of such atmospheres must be carried out from a holistic point of view. This paper aims to introduce a novel risk assessment and prioritization model, using hybrid AHP and VIKOR methods in a fuzzy environment. The AHP method was adopted to determine the importance (weight) of the risk influencing parameters. Also, the VIKOR as a compromise solution method was applied to rank the different working stations against the risk criteria. Fuzzy set theory was used to handle the inherent ambiguity and vagueness of the data encountered in the evaluation process. Furthermore, the fuzzy TOPSIS was adopted to further represent the efficacy of the proposed model. To demonstrate the applicability of the model, a small size foundry shop was selected as the real case and a sensitivity analysis was performed to confirm the validity of the model. The results revealed that the "Environment" has the most contribution to the risk level of hot environments $\left(\mathrm{W}_{\mathrm{E}}=0.615\right)$. That is followed by "Temperature" $\left(\mathrm{W}_{\mathrm{DBT}}=0.268\right)$, "Air velocity" $\left(\mathrm{W}_{\mathrm{AV}}=0.170\right)$, "Safety training" $\left(\mathrm{W}_{\mathrm{ST}}=0.161\right)$, "Mean radiant intensity" $\left(\mathrm{W}_{\mathrm{MRT}}=0.110\right)$, "Humidity" $\left(\mathrm{W}_{\mathrm{H}}=0.066\right)$, "Seniority structure" $\left(\mathrm{W}_{\mathrm{SS}}=0.063\right)$, "Work intensity" $\left(\mathrm{W}_{\mathrm{WI}}=0.058\right)$, "PPE" $\left(\mathrm{W}_{\mathrm{PPE}}=0.047\right)$, "Work nature" $\left(\mathrm{W}_{\mathrm{PPE}}=0.034\right)$, and "Work duration" $\left(\mathrm{W}_{\mathrm{T}}=0.022\right)$, in sub-factors. Using the F-VIKOR method, the "melting furnace" workstation was determined as the compromise solution with the index value of $\mathrm{Q}=1$.
\end{abstract}

Keywords Hot and humid environment · AHP · VIKOR · Fuzzy set · Foundry · Risk assessment

\section{Introduction}

High temperature indoor and outdoor environments are ubiquitous in industrial processes. Processes such as metal, glass, ceramic, and brick manufacturing, foundry, bakery, mining, and some military activities, expose the workers to

Supplementary Information The online version contains supplementary material available at https://doi.org/10.1007/ s00477-021-01995-1.

Mohsen Omidvar

m.omidvar@bpums.ac.ir; mohsenomidvar1359@gmail.com

Bahman Ramavandi

ramavandi_b@yahoo.com

Amir Hossein Darabi

hoseindarabi1970@gmail.com

1 Department of Environmental Health Engineering, Faculty of Health and Nutrition, Bushehr University of Medical

Sciences, Bushehr, Iran excessive heat (Zhang et al. 2021). Working in such environments can result in some physiological changes, such as increased heart rate, core body temperature (CBT), and sweat rate. Disruption of heat dissipation in such situations increases the CBT and eventually results in complications such as heat exhaustion, heat cramps, and in severe cases can give rise to death (Wang et al. 2010). The three most important diseases that can result from excessive heat accumulation in the body are heat cramps, heat exhaustion, and heat stroke (Parsons 2019). Hot-working environments can not only threaten occupational health but also raise the risk of accidents in workplaces (Chong et al.

2 Tropical Medicine Research Center, The Persian Gulf Biomedical Sciences Research Institute, Bushehr University of Medical Sciences, Bushehr, Iran

3 Department of Occupational Health Engineering, Faculty of Health and Nutrition, Bushehr University of Medical Sciences, Bushehr, Iran 
2020). Based on several surveys on the subject in Europe, Asia, Canada, the USA, and Australia, it has become revealed that occupational health and safety (OHS) and productivity can be compromised in hyperthermal environments (Hansen et al. 2020). The results of a metaanalysis (2000-2018) that analyzed three case-crossover and five time-series studies, in the US, Canada, Australia, Spain, Italy, and China, revealed a statistically significant increased pooled relative risk of occupational injuries associated with high-temperature environments (Binazzi et al. 2019). Dong et al. analyzed 791 heat-related deaths that occurred between 1992 and 2016 and reported the ratio of $36 \%$ for heat-related deaths among construction workers, a value about two times the ratio of $19.2 \%$ for workers in other industries (Dong et al. 2019). The burden of heatinduced adverse occupational health effects, as well as safety issues, is already considerable (Spector et al. 2019). Some studies reported significant losses in work capacity and productivity, with accompanying costs were $0.1-0.5 \%$ of GDP (Kjellstrom et al. 2016). The finding of Ėrica Martínez-Solanas et al. study showed an attribution of $2.72 \%$ of all occupational injuries and an annual economic burden of $0.03 \%$ of GDP to nonoptimal ambient temperatures (Martínez-Solanas et al. 2018).

To guarantee the workers' health and safety, numerous efforts have been made to develop indices that can reflect the effects of the different parameters in hot and humid environments. According to Brake and Bates (2002), over the last century, greater than 60 heat stress evaluation indices were developed to measure the heat stress in hot and humid environments nevertheless, no integrated index was universally accepted to assess these places. Traditionally, these indices are categorized as empirical and rational indices (Kjellstrom et al. 2016). Bethea and Parsons categorized these indices as (a) physiological strain (empirical) indices, (b) heat balance (rational) indices and (c) environmental parameters (direct) indices. Environmental parameters, such as ambient temperature (ta), wet bulb temperature $(\mathrm{Tw})$, relative humidity $(\mathrm{RH})$, wind speed (Va), and solar radiation (Rs), are used to derive direct indices. Rational indices are principally based on the energy-balance model of the human body and take into account the body's comfort by effective heat exchange over various environmental and behavioral ways (i.e. respiration, convention, conduction, radiation, metabolism, and so on) (Bethea and Parsons 2002). Although many organizations and researchers have provided different indicators for heat exposure; nevertheless, none of them have globally been accepted. Moreover, most of them were only dealing with the assessment of basic environmental and /or physiological parameters to evaluate safety in hot environments. Risk assessment of the work environment depends not only on the physical and physiological variables but also on many other complicating factors such as the nature of work, safety training, and personal protective equipment (PPE) usage, and so on. Hence, safety assessment of hot environments should be examined from a holistic standpoint which may be considered as a multiple criteria decision making (MCDM) problem (Zheng et al., 2012). Some efforts have been made to evaluate the safety of hot and humid work environments using MCDM methods. Ilangkumaran et al. (2015) applied the fuzzy ANP to evaluate the risk of the hot atmosphere in the foundry shop. They proposed a framework for the evaluation of criteria and a model for the determination of warning rating. In another survey, the fuzzy AHP was used to estimate the risk of hot and humid environments (Zheng et al. 2012). Golbabaie et al. (2019) developed a framework for risk assessment of heat stress of foundry workers, using the AHP and TOPSIS methods in the fuzzy environment. While these methods are valuable tools for evaluation of safety in hot and humid workplaces but, their deficiency to reflect the effect of criteria on the alternatives and differences in criteria units, limited their application.

The analytic hierarchy process (AHP) is an MCDM method intended to create a decision process in a scenario affected by multiple independent aspects (criteria) (Khashei-Siuki and Sharifan 2020). In the traditional AHP method, the scale of pairwise comparisons among criteria is limited to crisp numbers, besides it cannot take into consideration the vagueness associated with the mapping of expert's judgment to a number (Ayağ and Özdemir 2006). Consequently, this method is criticized for its unbalanced measure of judgment and deficiency to precisely handle the inherent hesitation and imprecision in performing pair-wise comparisons (Omidvar et al. 2017). Furthermore, all factors that affect the workers' safety in hot and humid environments do not have physical (measurable) characteristics. Because of the ineffectiveness of crisp numbers to quantify the behavioral and qualitative factors, such as safety training and PPE, we used the fuzzy sets to deal with this imprecision. Among the MCDM methods, the VIKOR is a compromise-based one that its objective is to solve decision problems with conflicting and non-commensurable (dissimilar units) criteria. The VIKOR method presents a ranking index, considering the specific measure of closeness to the ideal solution, and applies linear normalization to remove units of parameters.

As mentioned previously, different parameters can affect the risk level of hot and humid environments, some of them are possibly conflicting and non-commensurable. Among these parameters, some have qualitative nature (i.e., safety training, PPE usage, work nature, ...), while others have a quantitative feature (i.e., temperature, humidity, air velocity, radiant heat intensity). The first limitation of some previously conducted researches is that 
they have not considered the effect of these parameters simultaneously as an integrated index as well the effect of the conflicting and non-commensurable criteria. Another limitation is that in most of the works in this field the same importance is considered for the factors affecting the level of risk, while not all of them are of equal importance. On the other hand, the unit of measurement of all quantitative variables are not the same, this can cause errors when comparing different units in terms of the level of risk.

With regard to the capabilities and advantages of the AHP and VIKOR methods, this study aims to present a framework for the evaluation of safety in hot environments, applying the hybrid AHP-VIKOR methods in the fuzzy environment. The AHP method will be applied to determine the importance of the risk factors while the VIKOR will be used to evaluate the working station's status against the risk affecting factors as an integrated index. To the best of our knowledge, this is the first work that uses a compromise ranking method (VIKOR) accompanying the AHP method for risk evaluation of hot and humid environments.

\section{Methodology}

\subsection{Hot and humid environments risk assessment model}

The proposed model in this study contains three main stages: (a) determination of the criteria to be applied in the risk evaluation process and construction of the risk evaluation hierarchy (index system); (b) calculation of the criteria weights using fuzzy AHP method and (c) evaluation and prioritization of the risk in different workstations using the fuzzy VIKOR method. The proposed model is schematically illustrated in Fig. 1

\subsection{Analytical hierarchy process (AHP)}

The analytical hierarchy process (AHP) is one of the most commonly recognized methods in MCDM proposed by Saaty (2008). It is recognized as a structured method to establish and analyze intricate decisions, relying on mathematics and psychology. It characterizes a precise approach for determining the weights of decision criteria ( $\mathrm{Li}$ et al. 2019). It has a hierarchy structure that the goal of the decision is located at the top of the hierarchy with the bottom is composed of the alternatives. In AHP, individual knowledge and experiments are used to estimate the relative weights (importance) of parameters through pair-wise comparisons. Each of the experts has to juxtapose and compare the relative importance of the decision parameters in a pairwise manner via a specifically designed questionnaire by a Likert scale (Li et al. 2019). The most important advantage of AHP goes back to its unbiased and reasonable categorization system, and the ability to join in different assessment factors (Omidvar et al. 2017). However, due to the bias in human judgments and the faults that arise from pairwise comparisons of assessment parameters, the application of MCDM methods (AHP, ANP, VIKOR, etc.) is limited to some extent. These deficiencies have motivated academics to improve traditional MCDM. Due to the bias arises from subjective importance rating during the application of traditional AHP, the resulted weights are accompanied by some uncertainties. To improve the efficiency of the traditional AHP, fuzzy numbers (e.g., trapezoidal, triangular, Gaussian, and interval) have been used (Ghosh and Kar 2018). In the fuzzy AHP (F-AHP) method, the degree of relative importance in pairwise comparisons is characterized as fuzzy numbers, rather than a crisp number, which this fuzzy number can handle the uncertainty related to opinions as precisely as possible (Lyu et al. 2020).

\subsection{VIKOR Method}

The VIKOR method (a Serbian abbreviation that stands for VlseKriterijumska Optimizacija I Kompromisno Resenje) is a compromise ranking method that firstly was proposed by Serafim Opricovic (Opricovic and Tzeng 2004). The main objective of the VIKOR is to solve decision problems with conflicting and non-commensurable (dissimilar units) criteria. Considering that compromise is satisfactory for conflict resolution, the decision-maker wants a solution that is the closest to the ideal, and the alternatives are evaluated according to all established criteria (Akram et al. 2019). Like some other MCDM methods such as TOPSIS, VIKOR focuses on an aggregation function that characterizes closeness to the ideal, but different from TOPSIS, it applies linear normalization to remove units of criterion functions (Lee and Chang 2018). It is one of the MCDM methods that was established for ranking and selection of the optimum choice among a set of alternatives when there are conflicts between the criteria in complex systems. (Omidvar and Nirumand 2017). The basis for the development of the VIKOR method is the following Lp metric:

$L_{p, j}=\left\{\sum_{j=1}^{n}\left[\frac{w_{j}\left(\left|f_{j}^{*}-f_{i j}\right|\right)}{\left(\left|f_{j}^{*}-f_{j}^{-}\right|\right)}\right]^{p}\right\}^{1 / p}$

As the hot and humid environments influencing factors are conflicting in some cases (for example, while the "Temperature" is of the cost type, the "PPE" is of benefit kind), we were used the VIKOR method to rank and evaluate alternatives against risk factors. 


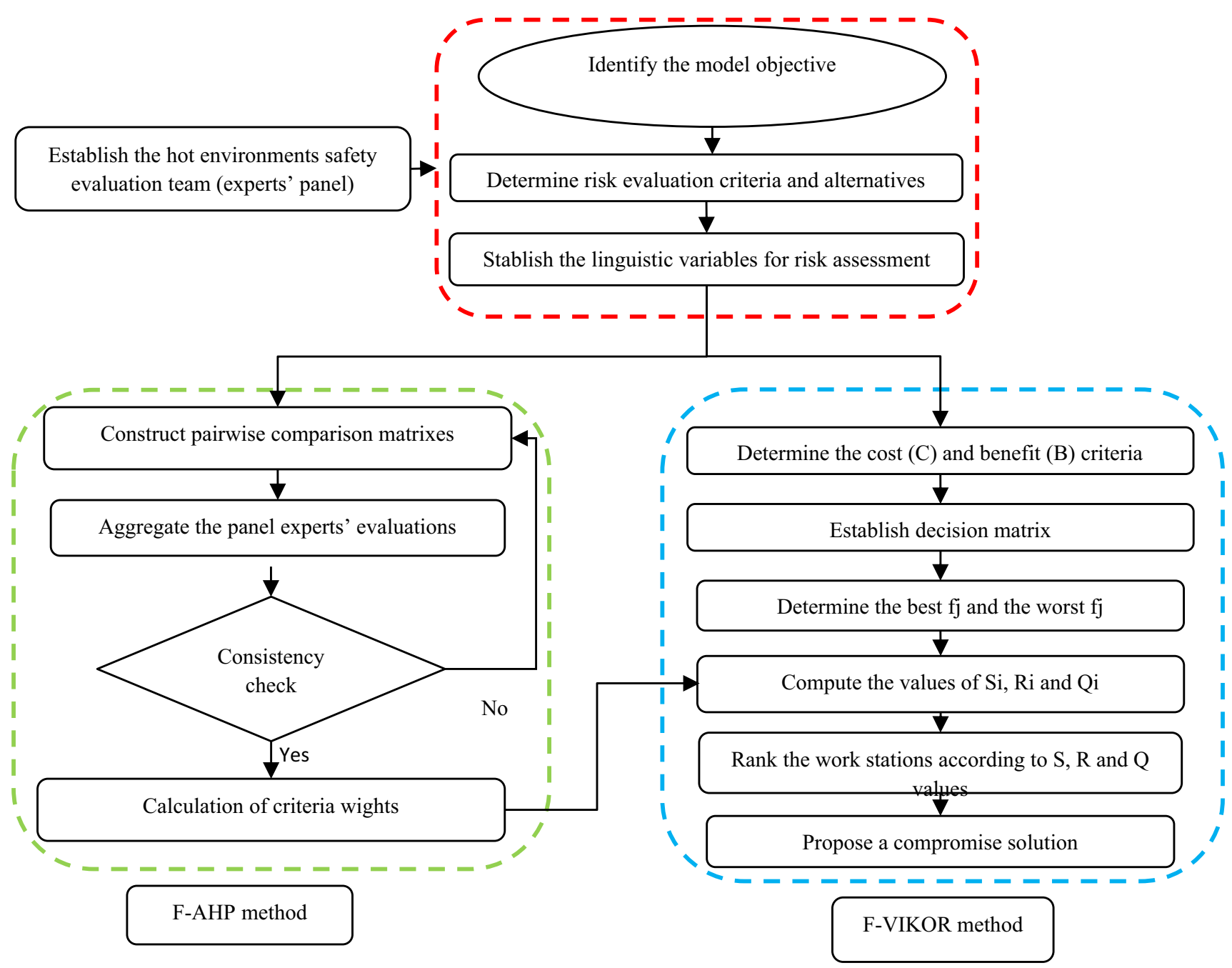

Fig. 1 Schematic illustration of the proposed model

\subsection{Fuzzy theory}

The human evaluation of qualitative characteristics is always subjective and therefore imprecise. In the real world, the decision-making process encompasses imprecision since goals, restrictions, and possible events are not defined accurately. To deal with this imprecision, the fuzzy logic introduced by Lotfi A. Zadeh (1965); a robust tool to cope with the uncertainty, vagueness, and ambiguity of mankind's judgment and evaluation in decision-making. That is more acceptable to translate the linguistic terms into fuzzy numbers, rather than to merging various knowledge, thoughts, ideas, and motivations of decisionmakers in linguistic form. In fact, a fuzzy number is a fuzzy set that possesses the conditions of normality and convexity (Nasseri 2008). There are different types of fuzzy numbers including triangle, trapezoid, singleton, Gaussian, and so forth. In this study, the TpFNs were adopted to determine the weight of criteria and evaluate (rank) the alternatives (workstations). A trapezoid fuzzy number (TpFN) can be expressed as a quadruplet $\tilde{A}=(l, m, n, u)$ where $1, \mathrm{~m}, \mathrm{n}$, and $\mathrm{u}$ denote lower, medium, and upper numbers of the fuzzy sets (Akyuz and Celik 2015). The membership function $\left(\mu_{\tilde{A}}\right)$ of a TpFN can be demonstrated as follows (Eq. 1):

$\mu_{\tilde{A}}(x)=\left\{\begin{array}{ll}0 & x<1 \\ \left(\frac{x-l}{m-l}\right) & l \leq x \leq m \\ 1 & m \leq x \leq n \\ \left(\frac{u-x}{u-n}\right) & n \leq x \leq u \\ 0 & x>u\end{array}\right\}$

Let $\tilde{A}$ and $\tilde{B}$ be two positive TpFNs expressed as $(\alpha 1, \alpha 2$, $\alpha 3, \alpha 4)$ and $(\beta 1, \beta 2, \beta 3, \beta 4)$, accordingly the algebraic operations of these two TpFNs can be accomplished as follows (Eqs. 2-5)) (Omidvar et al. 2017): 


$$
\begin{aligned}
& \text { Addition operation : } \tilde{A} \oplus \tilde{B} \\
& =[\alpha 1+\beta 1, \alpha 2+\beta 2, \beta 3+\alpha 3, \alpha 4+\beta 4]
\end{aligned}
$$

Subtraction operation : $\tilde{A} \ominus \tilde{B}=[\alpha 1-\beta 4, \alpha 2-\beta 3, \alpha 3-\beta 2, \alpha 4-\beta 1]$

Multiplication operation : $\tilde{A} \otimes \tilde{B}$

$$
=[\alpha 1 \beta 1, \alpha 2 \beta 2, \alpha 3 \beta 3, \alpha 4 \beta 4]
$$

Division operation : $\tilde{A} \varnothing \tilde{B}=[\alpha 1 / \beta 4, \alpha 2 / \beta 3, \alpha 3 / \beta 2, \alpha 4 / \beta 1]$

Table S1 (in supplementary section) was used to perform a pairwise comparison of the criteria by the panel experts. Also, Table S2 was utilized to obtain the panel experts' assessment of the workstations with respect to the evaluation criteria.

\subsection{Hot and humid environment safety assessment indexing system (HESEIS).}

To perform the risk assessment, initially, a framework was established to outline the process of risk assessment. The framework consists of the goal, attributes (criteria), subattributes (sub-criteria), and alternatives (work stations) as shown in Fig. 2 As seen from Fig. 2 the goal of this study was to evaluate the safety of hot and humid environments and to prioritize different workstations risk levels.

In this study, three main criteria and ten sub-criteria were considered for evaluation of heat stress as follow:

- Work

- Work nature (WN): This parameter denotes the dynamicity of the work. The more monotonous task, the more the fatigue and attention's deviation created by the work.

- Work intensity (WI): The amount of energy that workers deplete in a specific work. The more energy consumed, the more the CBT and risk generated by the work environment. As the temperature of the workplace increases, worker performance decreases.

- Work duration (WD): The amount of time that workers spend to perform a specific task in hot environments. Clearly, the more time spent, the more the risk imposed by the task.

- Environment (C2)

- Temperature (DBT): This parameter is known as dry-bulb temperature (DBT). It is the temperature of air measured by a general thermometer freely exposed to the air but protected from radiation and moisture. The more the DBT, the more the heat stress perceived by workers.
- Humidity (RH): This factor indicates the concentration (ratio) of water vapor present in the air and typically expresses as relative humidity $(\mathrm{RH} \%)$. The optimum quantity of RH is about 50-60\%.

- Airflow velocity (AV): Denotes the velocity of the air currents (draught) moving across the worker. As the air velocity increases, the worker feels a better sense about the workplace.

- Heat radiation intensity (RH): Also known as the mean radiant temperature (MRT) is described as the uniform temperature of an imaginary enclosure.

- Worker (C3)

- Seniority structure (SS): This item implies the expertise and adaptability of the worker

- Safety training (ST): The arrangement of safety toolboxes can reveal signs and symptoms of heat stress for workers and subsequently alert them to cope with the consequences of heat stress.

- Personal protection (PPE): As a barrier to prevent the effects of heat stress, protective equipment (PPEs) usage can beneficial for the wearers.

The abovementioned criteria were selected based on the literature review (Ilangkumaran et al. 2015; Wang et al. 2010; Zheng et al. 2012) nevertheless, confirmed by the experts' opinion.

\subsection{Determination of the criteria weights}

The fuzzy AHP (F-AHP) method was adopted to calculate the weight of the risk criteria. The process of determining the weights of the criteria and sub-criteria using the F-AHP is as follows:

\subsubsection{Establishing a panel of experts (i.e. $e_{1}, e_{2}, \ldots, e_{n}$ )}

Since different people may not agree on a specific issue completely, a team (panel of experts) was established to determine the weight of the indicators. To acquire representative opinions of panel experts, a questionnaire was designed and subsequently was delivered to them. The questionnaire was designed so that it could capture the opinions of the experts in a pairwise comparison structure. Because of the heterogeneity of the panel members in knowledge, experience, academic level, and their titles, an expert's coefficient was calculated (Table S3). The panel is composed of 10 members including two safety and health professionals, two process technicians, a foreman, four workers, and the foundry shop's manager. Establishing a team with the above specifications can provide realistic and reliable results (Zheng et al. 2012). This panel was established to determine the criteria of the problem and to 


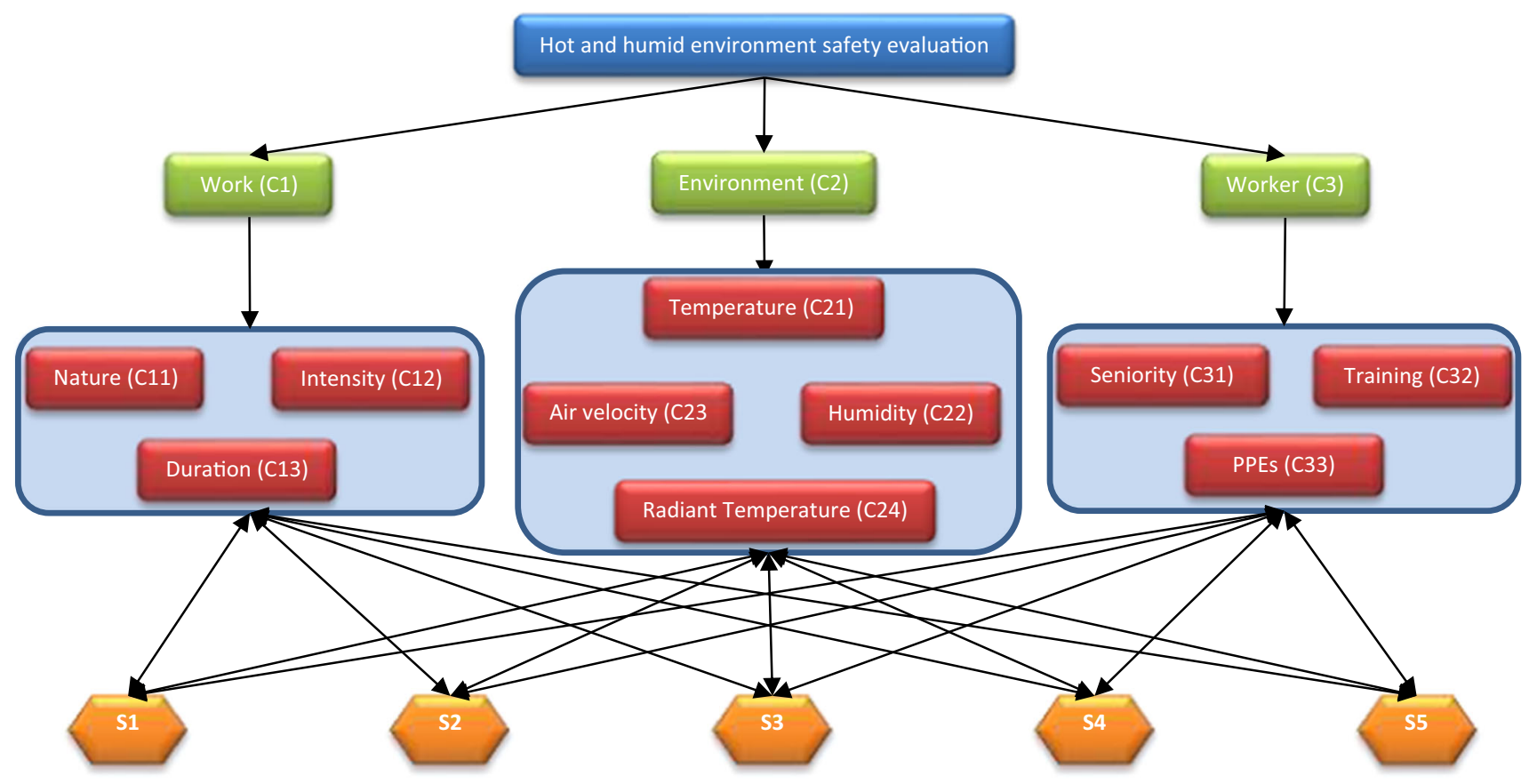

Fig. 2 Hot and humid environment safety assessment indexing system (HESEIS)

compare and evaluate the elements of the model (Criteria, sub-criteria, and alternatives).

\subsubsection{Determining the weights of criteria and sub-criteria of the problem}

\subsubsection{Pairwise comparison of the criteria and sub-criteria} by the experts In this step, each team member was requested to perform a pairwise comparison of the criteria and sub-criteria, considering the interdependency and consistency of the comparisons. A matrix a (PWC) was created according to the pair-wise comparison of criteria (C1 to $\mathrm{C} 3$ ) and sub-criteria (C1.1 to $\mathrm{C} 3.3)$.

$\tilde{a}=\left[\begin{array}{cccc}\tilde{a}_{11} & \tilde{a}_{12} & \ldots & \tilde{a}_{1 n} \\ \tilde{a}_{21} & \tilde{a}_{22} & \ldots & \tilde{a}_{2 n} \\ \vdots & \vdots & \ddots & \vdots \\ \tilde{a}_{n 1} & \tilde{a}_{n 2} & \ldots & \tilde{a}_{n n}\end{array}\right]$

Let the fuzzy rating of the $\mathrm{k}_{\mathrm{th}}$ decision-maker be $a_{i j}^{k}=\left(a_{i j 1}^{k}, a_{i j 2}^{k}, a_{i j 3}^{k}, a_{i j 4}^{k}\right) ; \mathrm{i}=1,2, \ldots, \mathrm{m}$ and $\mathrm{j}=1,2, \ldots, \mathrm{n}$. Therefore, the aggregated fuzzy ratings $\left(\tilde{a}_{i j}\right)$ of criteria can be calculated as Eqs. 7 and 8:

$\tilde{a}_{i j}=\left(l_{i j 1}, m_{i j 2}, n_{i j 3}, s_{i j 4}\right)$

where

$\tilde{a}_{i j 1}=\min a_{i j 1}^{k} \quad \tilde{a}_{i j 2}=\frac{1}{K} \sum_{K=1}^{K} a_{i j 2}^{K} \quad \tilde{a}_{i j 3}=\frac{1}{K} \sum_{K=1}^{K} a_{i j 3}^{K}$
$\tilde{x}_{i j 4}=\max a_{i j 4}^{k}$
2.6.2.2 Comparison's matrix consistency check An initial consistency check of aggregated pair-wise comparison matrixes was conducted before computing the weight of indicators. The process for consistency check was performed as follows:

2.6.2.3 Calculation of the largest eigenvalue of the comparison matrix The largest eigenvalue of the matrix was calculated from Eq. (9)

$X w=\lambda_{\max } \cdot w$

2.6.2.4 Determination of consistency ratio (CR) After determining the largest eigenvalue, the consistency ratio (CR) was computed as Eq. 10:

$C R=\frac{C I}{R I} ; C I=\left(\lambda_{\max }-n\right) /(n-1)$

where $C I$ indicates the consistency index, $R I$ denotes the random index which can be extracted from Table $\mathrm{S} 4$, and $n$ is the number of criteria that would be judged against (i.e. matrix size).

The consistency of the matrix is acceptable if $\mathrm{CR}<$ 0.10 ; otherwise, the pair-wise comparisons should be carried out again.

2.6.2.5 Calculation of the weights The Geometric mean method was adopted in this study to determine the criteria 
weights (Csutora and Buckley 2001). The following equations were used to determine the weight vector:

$\begin{aligned} \alpha_{j} & =\left[\prod_{j=1}^{n} l_{i j}\right]^{1 / n} ; \beta_{j}=\left[\prod_{j=1}^{n} m_{i j}\right]^{1 / n} ; \gamma_{j}=\left[\prod_{j=1}^{n} n_{i j}\right]^{1 / n} ; \delta_{j} \\ & =\left[\prod_{j=1}^{n} s_{i j}\right]^{1 / n} \text { and }\end{aligned}$

$\alpha=\sum_{j=1}^{n} \alpha_{j} ; \beta=\sum_{j=1}^{n} \beta_{j} ; \gamma=\sum_{j=1}^{n} \gamma_{j} ; \delta=\sum_{j=1}^{n} \delta_{j}$

The indicators weights were computed as:

$\tilde{w}_{j}=\left(\alpha_{j} \delta^{-1}, \beta_{j} \gamma^{-1}, \gamma_{j} \beta^{-1}, \delta_{j} \alpha^{-1}\right) \quad j \in\{1,2, \ldots, n\}$

Subsequently, the fuzzy weight vector $\tilde{w}_{j}$ was determined as:

$\tilde{W}=\left[\tilde{w}_{1} \tilde{w}_{2} \ldots \tilde{w}_{n}\right]$

\subsubsection{Ranking and prioritizing alternatives based on the VIKOR approach}

Ranking and prioritizing alternatives (work stations) based on the VIKOR approach was accomplished as below:

2.6.3.1 Construction of aggregated decision matrix: In this step, the panel's experts were requested to evaluate the workstations vs. risk factors (main criteria and sub-criteria). To accomplish this, a questionnaire was designed and delivered to them to perform the assessment. If the fuzzy rating (Table $S 2$ ) of $i_{\text {th }}$ alternative (work station) with regard to $\mathrm{j}_{\mathrm{th}}$ criterion (risk factor) of $\mathrm{k}_{\mathrm{th}}$ expert is presented as the fuzzy number $\tilde{x}_{i j k}=\left(x_{i j k 1}, x_{i j k 2}, x_{i j k 3}, x_{i j k 4}\right)$ then, the aggregated fuzzy rating of evaluation $\left(\tilde{x}_{i j k}\right)$ could be calculated as (Eq. 15):

$\left(\tilde{x}_{i j}=\left(x_{i j 1}, x_{i j 2}, x_{i j 3}, x_{i j 4}\right) \mid i=1,2, \ldots, m ; j=1,2, \ldots, n ; k=1,2, \ldots, K\right)$

and

$$
\left\{\begin{array}{c}
x_{i j 1}=\min _{k}\left\{x_{i j k 1}\right\} \\
x_{i j 2}=\frac{1}{k} \sum_{k=1}^{K} x_{i j k 2} \\
x_{i j 3}=\frac{1}{k} \sum_{k=1}^{K} x_{i j k 3} \\
x_{i j 4}=\max _{k}\left\{x_{i j k 4}\right\}
\end{array}\right.
$$

Furthermore, the decision matrix $\widetilde{\mathrm{D}}$ could be presented as:
$\tilde{D}=\left[\begin{array}{cccc}\tilde{x}_{11} & \tilde{x}_{12} & \ldots & \tilde{x}_{1 n} \\ \tilde{x}_{21} & \tilde{x}_{22} & \ldots & \tilde{x}_{2 n} \\ \vdots & \vdots & \ddots & \vdots \\ \tilde{x}_{m 1} & \tilde{x}_{m 2} & \ldots & \tilde{x}_{m n}\end{array}\right]$

2.6.3.2 Defuzzification of the decision matrix $\tilde{D}$ and fuzzy weights $\tilde{W}$ The following equation (Eq. 17) was applied to obtain the crisp (defuzzified) values of the decision matrix $\widetilde{\mathrm{D}}$.

$\operatorname{defuzz}(x i j)=\frac{-x_{i j 1} x_{i j 2}+x_{i j 3} x_{i j 4}+\frac{1}{3}\left(x_{i j 4}-x_{i j 3}\right)^{2}-\frac{1}{3}\left(x_{i j 2}-x_{i j 1}\right)^{2}}{-x_{i j 1}-x_{i j 2}+x_{i j 3}+x_{i j 4}}$

Correspondingly Eq. (13) was used to defuzzify the obtained aregated fuzzy weights from the AHP.

$\operatorname{defuzz}(w j)=\frac{-w_{j 1} w_{j 2}+w_{j 3} w_{j 4}+\frac{1}{3}\left(w_{j 4}-w_{j 3}\right)^{2}-\frac{1}{3}\left(w_{j 2}-w_{j 1}\right)^{2}}{-w_{j 1}-w_{j 2}+w_{j 3}+w_{j 4}}$

2.6.3.3 Determination of aspired (best $\mathrm{fj}^{*}$ ) and tolerable (worst $\mathrm{fj}^{-}$) level Aspired and tolerable levels characterize the best $\mathrm{fj}^{*}$ and the worst $\mathrm{fj}^{-}$values of all criterion ratings respectively and were computed as:

$f_{j}^{*}=\left\{\begin{array}{cc}\max _{i} x_{i j}, & \text { forbenefitcriteria } \\ \min _{i} x_{i j}, & \text { for } \cos \text { tcriteria }\end{array}\right\} f_{j}^{-}=\left\{\begin{array}{cc}\min _{i} x_{i j}, & \text { forbenefitcriteria } \\ \max _{i} x_{i j}, & \text { for } \cos \text { tcriteria }\end{array}\right\}$
$i=1,2, \ldots, m \quad:(j=1,2, \ldots, n)$

2.6.3.4 Calculation of the mean group utility $\left(S_{i}\right)$ and maximum regret $\left(\mathbf{R}_{i}\right.$ Mean group utility $\left(S_{i}\right)$ and maximum regret $\left(R_{i}\right)$ were calculated by Eq. 20

$S_{i}=\sum_{j=1}^{n}\left[\frac{w_{j}\left(\left|f_{j}^{*}-x_{i j}\right|\right)}{\left(\left|f_{j}^{*}-f_{j}^{-}\right|\right)}\right] ; \quad R_{i}=\max _{j}\left[\frac{w_{j}\left(\left|f_{j}^{*}-x_{k j}\right|\right)}{\left(\left|f_{j}^{*}-f_{j}^{-}\right|\right)}\right]$

2.6.3.5 Determination of the index value $(Q i, i=1,2, \ldots, m$, $)$ using Eq. (21) The index value $(\mathrm{Q})$ was determined using Eq. (21)

$$
\begin{aligned}
Q_{i} & =v \frac{S_{i}-S^{*}}{S^{-}-S^{*}}+(1-v) \frac{R_{i}-R^{*}}{R^{-}-R^{*}} \quad S^{*}=\min _{i}\left\{S_{i}\right\}, \\
S^{-} & =\max _{i}\left\{S_{i}\right\}, \quad R^{*}=\min _{i}\left\{R_{i}\right\}, \quad R^{-}=\max _{i}\left\{R_{i}\right\}
\end{aligned}
$$

In Eq. (15) the " $v$ " parameter presents the weight of the strategy of the maximum group utility; whereas $(1-v)$ denotes the weight of individual regret and its common value is 0.5 . 
2.6.3.6 Sorting and ranking the alternatives (work stations) In this step, all alternatives were arranged decreasingly with respect to the values of $S_{i}, R_{i}$, and $Q_{i}$. The results produce three ranking lists with reference to values of $S_{i}, R_{i}$ and $Q_{i}$.

2.6.3.7 Suggestion of compromise solution If the following two conditions are confirmed, the alternative $\mathrm{A}^{(1)}$ (which is the best ranked by the Q (minimum)) is suggested as the compromise solution (Opricovic and Tzeng 2007):

C1 Acceptable advantage: satisfies with $\mathrm{Q}\left(\mathrm{A}^{(2)}\right)-\mathrm{Q}$ $\left(\mathrm{A}^{(1)}\right) \geq \mathrm{DQ}$, which $\mathrm{DQ}=1 /(\mathrm{m}-1)$.

C2 Acceptable stability: The alternative $\mathrm{A}^{(1)}$ should also be the top-ranked by S or/and R. this is known as "voting by majority rule" for $\mathrm{v}>0.5$, "voting by consensus" for $\mathrm{v}=0.5$, or "with veto" for ( $\mathrm{v}<0.5)$.

when one of the above conditions is not fulfilled, a set of compromise solutions is proposed, as follows:

- Alternatives $\mathrm{A}(1)$ and $\mathrm{A}(2)$ as a compromise solution, if only the condition $\mathrm{C} 2$ is not satisfied or

- Alternatives $\mathrm{A}(1), \mathrm{A}(2), \ldots, \mathrm{A}(\mathrm{M})$ if the condition $\mathrm{C} 1$ is not fulfilled; $\mathrm{A}(\mathrm{M})$ is established by the $\mathrm{Q}(\mathrm{A}(\mathrm{M})) \mathrm{Q}($ $\mathrm{A}(1))<\mathrm{DQ}$ for maximum M. (Liu et al. 2012)

\subsubsection{Sensitivity analysis}

At the last step of the study, to investigate the validity of the proposed model, a sensitivity analysis was performed in terms of the weight of the strategy $(v)$. This parameter plays a significant role in the ranking of workstations (i.e., alternatives). The common value of $v$ is 0.5 ; though, it can take different quantities from 0 to 1 . This indicates that it is necessary to perform a sensitivity analysis in different values of $v$ to validate the obtained results.

\section{Case Study}

To demonstrate the applicability of the proposed model, a foundry shop (a real case) was selected as a representative of the hot environments. The foundry shop is located in Shiraz city, Iran. It is a small size factory that has employed about 40 workers. They work in two shifts (morning and evening shifts) and their work hardness is at an extreme level. The factory products include different parts of the cars (cylinder heads, gearbox housings, manifolds, pulleys, bearing, gears, etc.). Five steps (stations) of the work process were selected as the most critical ones and the risk evaluation was performed for them. They include scrap collection and dumping yard (A1), melting furnace charging station (A2), pouring and casting station (A3), casted components finishing area (A4), and depot area (A5). The only tool for the cooling of the workers was natural ventilation as well as a small size fan located at the corner of the shop (in front of the melting furnace). The physical parameters were measured by the approved tools and recorded for the subsequent analysis of the foundry stations.

\section{Results and Discussion}

To collect the required information, the experts firstly were requested to represent their idea about the importance of criteria and sub-criteria in terms of the scale (numbers) shown in Table S1 which then converted to equivalent fuzzy numbers. The aggregated evaluation results for the main criteria ( $\mathrm{C} 1$ to $\mathrm{C} 3)$ and sub-criteria $(\mathrm{C} 1.1$ to $\mathrm{C} 3.3)$ that were accomplished in pairwise comparisons are demonstrated in Table S5-S8.

Before calculating the criteria weights, the consistency of pairwise comparison matrixes was investigated using Eqs. 4 and 5. The results of the consistency check of the main criteria are listed in Table S9. It must be pointed out that all matrixes were consistent. The consistency ratio (CR) for all matrixes were computed and displayed in the last column of Tables S5-S8. After that, the importance (weights) of the main criteria and sub-criteria were determined according to Eqs. 6, 7, 8 and 9 as shown in Table 1 .

To compare the weights of the criteria a sub-criterion, the obtained fuzzy weights were firstly deffuzified using Eq. 12 and normalized subsequently. The results are demonstrated in Table 1. It clearly can be observed from Table 1 that the "Environment" $(\mathrm{C} 2)$ is gained the priority (greatest importance) amongst the main criteria, whereas the "Worker" (C3) and the "Work" (C1) are ranked as second and third, respectively. This indicates the greater contribution of "Environment" to the risk level of hot environments. Also, among the "Environment" sub-criteria, the "DBT" $(\mathrm{C} 2.1)$ is given the priority. This shows that the control of dry temperature has a prominent role in the control of risk levels. A little attention to Table 1 can be helpful. While the "DBT" (C2.1) is given priority in the "Environment" (C1) criteria group (local weight), it is also gained the first rank in all criteria (global weights). This is true for the second criteria i.e. "Air velocity". But this is not the case with other parameters. For example, while "Heat radiant intensity" (C2.4) is ranked third (local weight) within its group, it is ranked fourth among all variables (global weight). On the other hand, the "Safety training" (C3.2) is given the third rank amongst all criteria whereas it is gained the second rank in its group (local weight). In summary, the local weights for the main criteria 
Table 1 Local and global weights of the main and sub-criteria

\begin{tabular}{|c|c|c|c|c|c|c|c|c|c|}
\hline \multirow{2}{*}{$\frac{\text { Criteria }}{\text { Work }}$} & \multirow{2}{*}{$\frac{\mathrm{ID}}{\mathrm{C} 1}$} & \multicolumn{4}{|c|}{ Fuzzy weight vector } & \multirow{2}{*}{$\begin{array}{l}\text { Local weights } \\
0.114\end{array}$} & \multirow{2}{*}{$\frac{\text { Rank }}{3}$} & \multirow{2}{*}{$\begin{array}{l}\text { Global weights } \\
0.114\end{array}$} & \multirow{2}{*}{$\frac{\text { Rank }}{3}$} \\
\hline & & 0.076 & 0.090 & 0.137 & 0.178 & & & & \\
\hline Environment & $\mathrm{C} 2$ & 0.404 & 0.508 & 0.763 & 0.936 & 0.615 & 1 & 0.615 & 1 \\
\hline Worker & $\mathrm{C} 3$ & 0.165 & 0.211 & 0.336 & 0.438 & 0.271 & 2 & 0.271 & 2 \\
\hline Work nature & $\mathrm{C} 1.1$ & 0.110 & 0.222 & 0.368 & 0.801 & 0.295 & 2 & 0.034 & 9 \\
\hline Work intensity & $\mathrm{C} 1.2$ & 0.189 & 0.411 & 0.653 & 1.370 & 0.513 & 1 & 0.058 & 7 \\
\hline Work duration & $\mathrm{C} 1.3$ & 0.075 & 0.156 & 0.246 & 0.505 & 0.192 & 3 & 0.022 & 10 \\
\hline Temperature & $\mathrm{C} 2.1$ & 0.175 & 0.357 & 0.535 & 1.161 & 0.436 & 1 & 0.268 & 1 \\
\hline Humidity & $\mathrm{C} 2.2$ & 0.041 & 0.105 & 0.146 & 0.271 & 0.108 & 4 & 0.066 & 5 \\
\hline Air velocity & $\mathrm{C} 2.3$ & 0.094 & 0.229 & 0.340 & 0.755 & 0.277 & 2 & 0.170 & 2 \\
\hline Heat radiant intensity & $\mathrm{C} 2.4$ & 0.063 & 0.131 & 0.196 & 0.505 & 0.179 & 3 & 0.110 & 4 \\
\hline Seniority structure & $\mathrm{C} 3.1$ & 0.103 & 0.181 & 0.275 & 0.578 & 0.233 & 2 & 0.063 & 6 \\
\hline Safety training & $\mathrm{C} 3.2$ & 0.235 & 0.510 & 0.770 & 1.426 & 0.593 & 1 & 0.161 & 3 \\
\hline PPE & C3.3 & 0.069 & 0.119 & 0.189 & 0.459 & 0.174 & 3 & 0.047 & 8 \\
\hline
\end{tabular}

(C1-C3) can be shown as $\mathrm{W}_{\mathrm{C} 2}=(0.615)>\mathrm{W}_{\mathrm{C} 3-}$ $=(0.271)>\mathrm{W}_{\mathrm{C} 1}=(0.114)$. If one wants to determine the importance of a parameter, it is necessary to consider the effect of all criteria. Then, it is preferable to utilize global wights in the risk assessment process. The global wights of the main criteria and sub-criteria is calculated as " $\mathrm{W}_{\mathrm{C} 2 \text {.1- }}$ $=0.268, \mathrm{~W}_{\mathrm{C} 2.3}=0.170, \mathrm{~W}_{\mathrm{C} 3.2}=0.161, \mathrm{~W}_{\mathrm{C} 2.4}=0.110$, $\mathrm{W}_{\mathrm{C} 2.2}=0.066, \quad \mathrm{~W}_{\mathrm{C} 3.1}=0.063, \quad \mathrm{~W}_{\mathrm{C} 1.2}=0.058, \quad \mathrm{~W}_{\mathrm{C} 3.3-}$ $=0.047, \mathrm{~W}_{\mathrm{C} 1.1}=0.039, \mathrm{~W}_{\mathrm{C} 1.3}=0.022$ ", in a decreasing order. It can be seen from the last column of Table 1 that the five variables with the more importance in contrast with other parameters are "Temperature (DBT)", "Air velocity (AV)", "Safety training (ST)", "Heat radiant intensity (MRT)", and "Work intensity (WI)" respectively. That is reasonable that these physical parameters gain the abovementioned weights. The DBT has a direct impact on other "Environment" sub-criteria. The MRT, AV, and RH are related directly to DBT (Parsons 2019). Referring to ISO 7243:2017 (International Organization for Standardization 2017), a universally accepted index for evaluation of physical aspects of hot and humid environments, the DBT, AV, MRT, and WI as the environmental (physical) parameters, are included in WBGT (Wet Bulb Globe Temperature) index. The WBGT equation combines the DBT, MRT as well, the wet-bulb temperature (and indirectly $\mathrm{RH}$ ) to establish the standard threshold limit values (TLVs) of working in hot and humid environments (DHSS 2018). The coefficient of the abovementioned parameters in the WBGT index is consistent with the weights are calculated in this study. Albeit, three physical parameters (DBT, MRT, and wet bulb temperature) are applied directly in the WBGT index calculation formula, but it incorporates the effects of clothing, air velocity, and work- rest schedules (work intensity) as a "correction coefficient" to establish the standard values of the WBGT. The safety training of workers about the risks that threaten them in such atmospheres and how to cope with them is a priority. Training of workers about how and when using the PPEs, how to monitor symptoms of heat stress (heat stain), and how to implementing work-rest schedules, can promote the safety of hot environments (Parsons 2019). The National Institute of Occupational Safety and Health (NIOSH) offers working practices for hot environments in terms of engineering and administrative controls, heat alert programs, protective clothing (PPE), and performance degradation and acclimatization. The NIOSH emphasis that "heat stress training program should be in place for all who work in hot environments and their supervisors" (DHSS 2018).

Using the crisp values of physical parameters (C2) acquired by measuring devices and fuzzy evaluation vectors obtained from the panel members' opinions ( $\mathrm{C} 1$ and $\mathrm{C} 3$ ), the risk prioritization of the work stations was performed by the F-VIKOR method. Table 2 shows the measured values of the "Environment" criteria plus the "Work duration" parameter. Table 3 also demonstrates the results of the panel member's evaluation of work stations vs. the subjective parameters of the risk evaluation index system.

Aggregated fuzzy evolution (AFVs) values are shown in the last four columns of Table 3. Considering the AFVs, the defuzzified values of AFVs were calculated using Eq. 12 and the results are tabulated in Table 4.

Table S10 represents the values of aspired (best $\mathrm{fj}^{*}$ ) and tolerable (worst $\mathrm{fj}^{-}$) levels. By setting the weight of the strategy value $(v)$ equal to 0.5 , values of $S, R$, and $Q$ were determined as shown in Table S11. 
As can be observed from Table S11, the "Pouring and casting" station (A3) is clearly the worst station from the risk level standpoint, according to $\mathrm{Q}$ values, and should be given the top rank in all stations. The priority of the other stations can be followed as A2 $>$ A4 $>$ A5 $>$ A1. Referring to the fulfillment's conditions of an alternative as a compromise solution, it is observed that A3 has been ranked first in all three values $\mathrm{R}, \mathrm{S}$, and $\mathrm{Q}$ values; but to be selected as the compromise solution, it is necessary to initially investigate the first condition (i.e. acceptable advantage). To verify this, the DQ value is determined as $\mathrm{DQ}=1 /(5-1)=0.25 ;$ so, the condition of $\mathrm{Q}\left(\mathrm{A}^{(2)}\right)$ $\mathrm{Q}\left(\mathrm{A}^{(1)}\right)=1-0.64=0.36>0.25$ is verified. On the other hand, alternative $A^{(1)}$ (Pouring and casting station) also is best ranked by $S$ and $R$ values $\left(S_{A(1)}=0.612\right.$ and $R$ $A(1)=0.259)$. So, the second condition (i.e. Acceptable stability) also is verified. In other words, A3 can be selected as the compromise solution. While at the first glance it seems that the "Melting furnace" (A2) should get the first rank (because of having the worst condition in relation to environmental criteria), but as it located outdoor (benefits from natural ventilation draughts) and the workers are forced to spend less time nearby the melting furnace, consequently this caused that it's priority changes to second and A3 is gained the priority.

The results of the F-TOPSIS analysis are shown in Table S12. The values of the fuzzy positive-ideal solution (FPIS, A*), and Fuzzy negative-ideal solution (FNIS, A-) distances, and similarity to an ideal solution (closeness coefficient) are tabulated in Table S12. Finally, the comparative results of the ranking of workstations (alternatives) as per closeness rating in F-TOPSIS and index value (Q) in F-VIKOR, in descending order are shown in Table 5.

It can be observed from Table 5 that the ranking sequence of the five workstations (A1-A5) acquired by the fuzzy TOPSIS is somewhat different from those achieved by the proposed approach. The ranking of the A2, A3, and A4 is the same, but the priority of A1 and A5 are in contrast together. The main cause of this dissimilarity is lying in the features of TOPSIS and VIKOR methods. This is partly due to the difference in the approaches that these two methods utilize to aggregate the decision matrix. While the VIKOR method is rooted in an aggregating function that demonstrates the distance from the ideal solution, the TOPSIS is established based on the axiom that the optimal point should have the shortest distance from the positive ideal solution and the farthest from the negative ideal solution. the second reason for this difference is the type of normalization approach that they implement to remove the units of the criteria functions; whereas the VIKOR applies linear normalization, the TOPSIS uses vector normalization.

The results of the sensitivity analysis based on " $v$ " values are depicted in Fig. 3. As it can be observed, the rankings of the "Pouring and casting" station (A3) and "Scrap collection and dumping" station (A1) are not influenced by using different values of $v$. This indicates that the risk priority of these two alternatives is analogous in terms of both minimum individual regret (MIR) and maximum group utility (MGU) values; and despite the changes in values of $v, A 3$ has remained as the compromise solution. These results denote the robustness and reliability of the results obtained by the suggested approach.

Returning to Fig. 3, it can be seen that the trend of "Casted components polishing" satiation (A4) is changed in a way that it is obtained lower $Q$ values (i.e. it was gained lower risk priority) in lower values of $v$, but with increasing the value of $v(v>0.5)$ this trend is reversed so that the risk priority of the A4 is inclined (i.e. it is aggravated). For the "Melting furnace" (A2) this trend is repeated but in exactly the opposite direction. This fact reveals that when focusing on MGU, the risk level of A4 will be increased while focusing on the MIR risk level of A2 will be aggravated. In other words, while the panel experts focus on MIR, the A2 has a lower rank than A4, nevertheless, this will be reversed when one focuses on MGU.

One limitation of this study is the application of a subjective weighting method for the determination of the criteria weights. It is proposed that for future works, researchers use the objective weighting methods accompanied with the subjective weighting to determine the relative importance of the criteria. While subjective

Table 2 The measurement values of the "Environment" criteria plus the "Work duration" parameter

\begin{tabular}{|c|c|c|c|c|c|}
\hline & $\begin{array}{l}\text { Work } \\
\text { duration (h) } \\
\text { C13 }\end{array}$ & $\begin{array}{l}\text { Temperature } \\
\left({ }^{\circ} \mathrm{C}\right) \\
\mathrm{C} 21\end{array}$ & $\begin{array}{l}\text { Humidity } \\
(\mathrm{RH} \%) \\
\mathrm{C} 22\end{array}$ & $\begin{array}{l}\text { Air velocity } \\
(\mathrm{m} / \mathrm{s}) \\
\mathrm{C} 23\end{array}$ & $\begin{array}{l}\text { Heat radiant } \\
\text { intensity }\left({ }^{\circ} \mathrm{C}\right) \\
\mathrm{C} 24\end{array}$ \\
\hline A1 & 3 & 26 & 60 & 0.20 & 29 \\
\hline A2 & 4 & 34 & 42 & 0.60 & 41 \\
\hline A3 & 6 & 35 & 43 & 0.50 & 43 \\
\hline A4 & 8 & 32 & 47 & 0.40 & 34 \\
\hline A5 & 5 & 25 & 59 & 0.20 & 28 \\
\hline
\end{tabular}


Table 3 Fuzzy evaluation numbers of workstations vs. risk criteria

\begin{tabular}{|c|c|c|c|c|c|c|c|c|c|c|c|c|c|c|c|}
\hline & & \multirow[t]{2}{*}{ E1 } & \multirow[t]{2}{*}{ E2 } & \multirow[t]{2}{*}{ E3 } & \multirow[t]{2}{*}{ E4 } & \multirow[t]{2}{*}{ E5 } & \multirow[t]{2}{*}{ E6 } & \multirow[t]{2}{*}{ E7 } & \multirow[t]{2}{*}{ E8 } & \multirow[t]{2}{*}{ E9 } & \multirow[t]{2}{*}{ E10 } & \multicolumn{4}{|c|}{ Aggregated values of evolution } \\
\hline & & & & & & & & & & & & $\mathrm{L}$ & M & $\mathrm{N}$ & $\mathrm{U}$ \\
\hline \multirow[t]{5}{*}{ A1 } & $\mathrm{C} 11$ & VG & VG & G & VG & $\mathrm{G}$ & $\mathrm{VP}$ & VG & VG & VG & VG & 7 & 7.9 & 8.7 & 9 \\
\hline & $\mathrm{C} 12$ & M & $\mathrm{P}$ & VG & M & M & M & $\mathrm{VP}$ & M & M & M & 3.7 & 4.6 & 4.8 & 5.7 \\
\hline & $\mathrm{C} 31$ & MP & VP & MP & MG & MP & MP & MP & MP & MP & G & 2.6 & 3.5 & 4.4 & 5.4 \\
\hline & C32 & MG & $\mathrm{M}$ & VP & $\mathrm{MG}$ & $\mathrm{MG}$ & MG & MG & $\mathrm{MG}$ & $\mathrm{P}$ & MG & 4 & 4.9 & 5.7 & 6.7 \\
\hline & C33 & $\mathrm{MP}$ & $\mathrm{MP}$ & MP & $\mathrm{MG}$ & $\mathrm{MP}$ & $\mathrm{G}$ & $\mathrm{P}$ & $\mathrm{MP}$ & MP & $\mathrm{M}$ & 2.9 & 3.9 & 4.6 & 5.6 \\
\hline \multirow[t]{5}{*}{ A2 } & C11 & $\mathrm{P}$ & $\mathrm{P}$ & VG & $\mathrm{P}$ & $\mathrm{P}$ & MG & $\mathrm{P}$ & $\mathrm{MP}$ & $\mathrm{P}$ & $\mathrm{P}$ & 2.2 & 3.2 & 3.5 & 4.4 \\
\hline & $\mathrm{C} 12$ & VG & VG & VG & VG & VG & VG & M & VG & VG & $\mathrm{G}$ & 7.5 & 8.5 & 9.3 & 9.5 \\
\hline & C31 & G & MG & $\mathrm{G}$ & MP & $\mathrm{G}$ & M & $\mathrm{G}$ & $\mathrm{M}$ & $\mathrm{G}$ & $\mathrm{G}$ & 5.7 & 6.7 & 6.9 & 7.9 \\
\hline & C32 & MG & MG & M & $\mathrm{MG}$ & MG & M & $\mathrm{P}$ & MG & MG & MG & 4.4 & 5.4 & 6.1 & 7.1 \\
\hline & C33 & $\mathrm{G}$ & $\mathrm{G}$ & VP & $\mathrm{G}$ & $\mathrm{G}$ & VG & $\mathrm{G}$ & $\mathrm{G}$ & $\mathrm{G}$ & $\mathrm{P}$ & 5.8 & 6.7 & 6.9 & 7.8 \\
\hline \multirow[t]{5}{*}{ A3 } & C11 & $\mathrm{P}$ & $\mathrm{MG}$ & $\mathrm{P}$ & $\mathrm{P}$ & $\mathrm{P}$ & MP & $\mathrm{P}$ & $\mathrm{P}$ & $\mathrm{P}$ & MP & 1.6 & 2.6 & 2.9 & 3.9 \\
\hline & $\mathrm{C} 12$ & $\mathrm{VG}$ & $\mathrm{VG}$ & $\mathrm{VG}$ & $\mathrm{M}$ & VP & $\mathrm{VG}$ & MG & VG & VG & VG & 6.5 & 7.4 & 8.3 & 8.6 \\
\hline & C31 & $\mathrm{G}$ & M & $\mathrm{G}$ & $\mathrm{G}$ & G & MG & $\mathrm{G}$ & MG & G & $\mathrm{M}$ & 6 & 7 & 7.2 & 8.2 \\
\hline & C32 & MG & $\mathrm{P}$ & MG & VG & MG & MG & MG & MG & VG & MG & 5.2 & 6.2 & 7.1 & 7.9 \\
\hline & C33 & $\mathrm{G}$ & $\mathrm{G}$ & $\mathrm{G}$ & $\mathrm{G}$ & MG & MP & $\mathrm{G}$ & $\mathrm{G}$ & MG & $\mathrm{G}$ & 6.1 & 7.1 & 7.4 & 8.4 \\
\hline \multirow[t]{5}{*}{ A4 } & C11 & MP & $\mathrm{MG}$ & MP & MP & MP & MP & $\mathrm{G}$ & MP & MP & MG & 3.1 & 4.1 & 5 & 6 \\
\hline & $\mathrm{C} 12$ & $\mathrm{M}$ & M & MG & VG & MG & $\mathrm{M}$ & M & M & $\mathrm{M}$ & $\mathrm{M}$ & 4.6 & 5.6 & 5.9 & 6.8 \\
\hline & C31 & MP & $\mathrm{M}$ & MP & MP & MP & VP & MP & MP & $\mathrm{P}$ & MP & 1.9 & 2.8 & 3.6 & 4.6 \\
\hline & C32 & MG & $\mathrm{MG}$ & $\mathrm{MG}$ & $\mathrm{MG}$ & G & VP & MG & $\mathrm{MG}$ & MP & $\mathrm{G}$ & 4.6 & 5.5 & 6.3 & 7.3 \\
\hline & C33 & MP & MG & MP & MP & MP & MP & MP & MP & G & MP & 2.8 & 3.8 & 4.7 & 5.7 \\
\hline \multirow[t]{5}{*}{ A5 } & C11 & VG & VG & MG & VG & VG & MG & G & VG & MG & VG & 7 & 8 & 8.9 & 9.3 \\
\hline & $\mathrm{C} 12$ & $\mathrm{P}$ & $\mathrm{P}$ & $\mathrm{P}$ & MG & $\mathrm{P}$ & $\mathrm{P}$ & MG & $\mathrm{P}$ & VG & MP & 2.6 & 3.6 & 4 & 4.9 \\
\hline & C31 & $\mathrm{P}$ & MP & VG & $\mathrm{P}$ & $\mathrm{P}$ & $\mathrm{P}$ & VP & $\mathrm{P}$ & G & $\mathrm{P}$ & 2.3 & 3.2 & 3.5 & 4.4 \\
\hline & C32 & $\mathrm{P}$ & $\mathrm{P}$ & $\mathrm{P}$ & $\mathrm{P}$ & VP & $\mathrm{P}$ & MG & VP & $\mathrm{P}$ & $\mathrm{P}$ & 1.2 & 2 & 2.3 & 3.3 \\
\hline & C33 & VP & VG & VP & MP & $\mathrm{G}$ & $\mathrm{VP}$ & $\mathrm{VP}$ & VP & VP & VP & 1.7 & 2 & 2.9 & 3.8 \\
\hline
\end{tabular}

Table 4 Defuzzified values of the "Work" and "Worker" subcriteria

Table 5 Final ranking of the workstations

\begin{tabular}{llllll}
\hline $\begin{array}{l}\text { Criteria } \\
\text { ID }\end{array}$ & Work nature & Work intensity & Seniority structure & Safety training & PPE \\
C 1.1 & C1.2 & C3.1 & C3.3 \\
\hline A1 & 8.13 & 4.70 & 3.98 & 5.33 & 4.25 \\
A2 & 3.32 & 8.67 & 6.80 & 5.75 & 6.80 \\
A3 & 2.75 & 7.68 & 7.10 & 6.59 & 7.25 \\
A4 & 4.55 & 5.72 & 3.23 & 5.93 & 4.25 \\
A5 & 8.28 & 3.77 & 3.35 & 2.21 & 2.62 \\
\hline
\end{tabular}

\begin{tabular}{|c|c|c|c|c|c|c|c|c|}
\hline \multirow[t]{2}{*}{ Alternative } & \multicolumn{6}{|c|}{ F-VIKOR } & \multicolumn{2}{|c|}{ F-TOPSIS } \\
\hline & $\mathrm{S}$ & Ranking & $\mathrm{R}$ & Ranking & Q & Ranking & $\mathrm{CC}$ & Ranking \\
\hline A1 & 0.713 & 5 & 0.300 & 5 & 0.000 & 5 & 0.344 & 4 \\
\hline $\mathrm{A} 2$ & 0.822 & 4 & 0.420 & 2 & 0.640 & 2 & 0.802 & 2 \\
\hline A3 & 0.908 & 1 & 0.467 & 1 & 1.000 & 1 & 0.834 & 1 \\
\hline A4 & 0.907 & 2 & 0.327 & 3 & 0.578 & 3 & 0.614 & 3 \\
\hline A5 & 0.881 & 3 & 0.301 & 4 & 0.429 & 4 & 0.139 & 5 \\
\hline
\end{tabular}


Fig. 3 Sensitivity analysis of 412 the F-VIKOR results

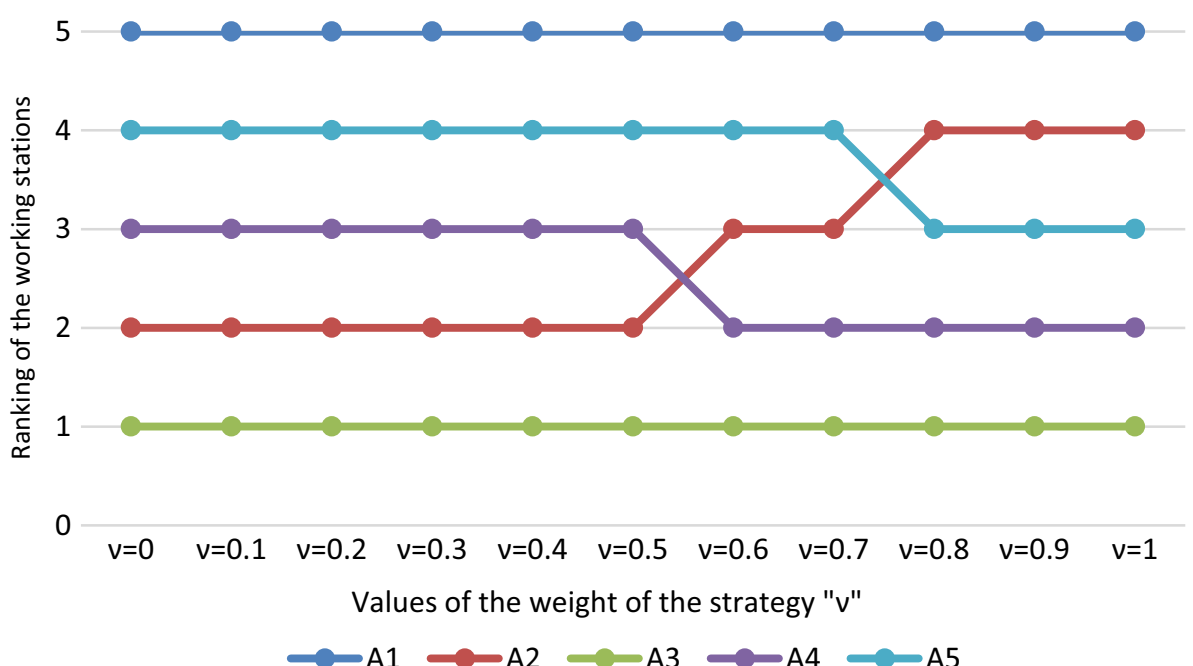

methods establish weights exclusively based on the preference or judgments of experts, objective methods use mathematical models, like entropy or multiple-objective programming (MOP) method, without considering the experts' preferences (Shemshadi et al. 2011).

\section{Conclusion}

In this study, an integrated fuzzy AHP-VIKOR method was adopted to assess the safety level in hot and humid environments. A safety evaluation framework was established based on 3 main criteria and 10 sub-criteria. The fuzzy AHP method was used to calculate the weight of the criteria, while the fuzzy VIKOR method was applied to prioritize the risk of different work stations considering the qualitative and quantitative criteria in the process of the risk assessment. To demonstrate the applicability of the model, a foundry shop was selected as a representative of hot atmospheres and the proposed model was implemented practically. The results revealed that the "Environment" has the most contribution to the risk level of hot environments $\left(\mathrm{W}_{\mathrm{E}}=0.615\right)$. That is followed by "Temperature" $\left(\mathrm{W}_{\mathrm{DBT}}=0.268\right)$, "Air velocity" $\left(\mathrm{W}_{\mathrm{AV}}=0.170\right)$, "Safety training" $\left(\mathrm{W}_{\mathrm{ST}}=0.161\right)$, "Mean radiant intensity" $\left(\mathrm{W}_{\mathrm{MRT}}=0.110\right)$, "Humidity" $\left(\mathrm{W}_{\mathrm{H}}=0.066\right)$, "Seniority structure" $\quad\left(\mathrm{W}_{\mathrm{SS}}=0.063\right)$, "Work intensity" $\left(\mathrm{W}_{\mathrm{WI}-}\right.$ $=0.058)$, "PPE" $\left(\mathrm{W}_{\mathrm{PPE}}=0.047\right), \quad$ "Work nature" $\left(\mathrm{W}_{\mathrm{PPE}}=0.034\right)$, and "Work duration" $\left(\mathrm{W}_{\mathrm{T}}=0.022\right)$, in sub-factors. Using the F-VIKOR method, the "melting furnace" workstation was determined as the compromise solution with the index value of $Q=1$. Although the proposed model is used and verified in a foundry shop, it can be generalized for implementation in other hot and humid environments due to its flexible structure. For future works, it can be recommended that researchers use the objective weighting methods accompanied with the subjective weighting to determine the relative importance of the criteria.

List of symbols TpFN: Trapezoid fuzzy number; $L_{p, j}$ : Distance of the alternative $\mathrm{Aj}$ from the best ideal solution; $w_{j}$ : Weight (relative importance) of $j$ th criterion; $f_{i j}$ : Measured score of the jth alternative (Aj) against the ith criteria $(\mathrm{Ci}) ; f_{j}^{*}$ : The best values of all criterion ratings; $f_{j}^{-}$: The worst values of all criterion ratings; $\mu_{\tilde{A}}(x)$ :

Membership function of a TpFN; $L, m, n, u$ : Lower, mide, and upper numbers of the fuzzy set; $\tilde{A,} \tilde{B}$ : Two positive TpFNs; $\oplus, \ominus, \otimes, \varnothing$ : Addition, Subtraction, Multiplication, and Division operators of TpFNs; $\tilde{a}$ : Pair-wise comparison matrices of the criteria; $a_{i j}^{k}$ : Fuzzy rating of the $\mathrm{k}_{\mathrm{th}}$ decision-maker; $\tilde{a}_{i j}$ : Aggregated fuzzy ratings $\left(\tilde{a}_{i j}\right)$ of criteria; CI: Consistency index; RI: Random index; CR: Consistency ratio; $\lambda_{\max }$ : Largest eigenvalue of the matrix; $\alpha, \beta, \gamma, \delta$ : Geometric mean of the lower, middle, and upper numbers of the fuzzy number; $\tilde{W}$ : Fuzzy weight vector; $\tilde{w}_{j}$ : Indicators weights; $\left(\tilde{x}_{i j k}\right)$ : Aggregated fuzzy rating of evaluation; $\tilde{D}$ : Decision matrix; defuzz(xij): Defuzzified values of the decision matrix; $\operatorname{defuzz}(w j)$ : Defuzzified values of the fuzzy weights; $S_{\mathrm{i}}, R_{\mathrm{i}}$ : Mean group utility and maximum regret values; $\mathrm{Q}$ : Index value; $v$ : Weight of the maximum group utility (weight of the strategy); $1-v$ : Weight of individual regret

Acknowledgments This research has been supported by Bushehr University of Medical Sciences, Iran (Grant No. BPUMS-213H-20).

\section{Declarations}

Conflict of interest The authors declare that they have no known competing financial interests or personal relationships that could have appeared to influence the work reported in this paper. 


\section{References}

Akram M, Al-Kenani AN, Alcantud JCR (2019) Group decisionmaking based on the VIKOR method with trapezoidal bipolar fuzzy information. Symmetry 11(10):1313

Akyuz E, Celik E (2015) A fuzzy DEMATEL method to evaluate critical operational hazards during gas freeing process in crude oil tankers. J Loss Prev Process Ind 38:243-253

Ayağ Z, Özdemir RG (2006) A fuzzy AHP approach to evaluating machine tool alternatives. J Intell Manuf 17(2):179-190

Bethea D, Parsons K 0(2002) Health and safety executive staff. Development of a Practical Heat Stress Assessment Methodology for Use in UK Industry. HSE Books, London

Binazzi A, Levi M, Bonafede M, Bugani M, Messeri A, Morabito M, Baldasseroni A (2019) Evaluation of the impact of heat stress on the occurrence of occupational injuries: meta-analysis of observational studies. Am J Ind Med 62(3):233-243

Brake R, Bates G (2002) A valid method for comparing rational and empirical heat stress indices. Ann Occup Hyg 46(2):165-174

Chong D, Zhu N, Luo W, Zhang Z, Pan X (2020) Effects of heat acclimation on individual safety performance in hyperthermal indoor environments. Build Environ 168:106537

Csutora R, Buckley JJ (2001) Fuzzy hierarchical analysis: the Lambda-Max method. Fuzzy Sets Syst 120(2):181-195

DHSS. (2018). NIOSH criteria for a recommended standard: occupational exposure to heat and hot environments: National Institute on Drug Abuse.

Dong XS, West GH, Holloway-Beth A, Wang X, Sokas RK (2019) Heat-related deaths among construction workers in the United States. Am J Ind Med 62(12):1047-1057. https://doi.org/10. 1002/ajim.23024

Gasparrini A, Guo Y, Hashizume M, Lavigne E, Zanobetti A, Schwartz J, Armstrong B (2015) Mortality risk attributable to high and low ambient temperature: a multicountry observational study. The Lancet 386(9991):369-375. https://doi.org/10.1016/ S0140-6736(14)62114-0

Ghosh A, Kar SK (2018) Application of analytical hierarchy process (AHP) for flood risk assessment: a case study in Malda district of West Bengal India. Nat Hazards 94(1):349-368

Golbabaei F, Omidvar M, Nirumand F (2019a) Risk assessment of heat stress using the AHP and TOPSIS methods in fuzzy environment: a case study in a foundry shop. J Health Safety Work 8(4):397-408

Hansen AL, Williams S, Hanson-Easey S, Varghese BM, Bi P, Heyworth J, Pisaniello DL (2020) Using a qualitative phenomenological approach to inform the etiology and prevention of occupational heat-related injuries in Australia. Int J Environ Res Public Health 17(3):846

Ilangkumaran M, Karthikeyan M, Ramachandran T, Boopathiraja M, Kirubakaran B (2015) Risk analysis and warning rate of hot environment for foundry industry using hybrid MCDM technique. Saf Sci 72:133-143. https://doi.org/10.1016/j.ssci.2014. 08.011

Inaba R, Mirbod SM (2007) Comparison of subjective symptoms and hot prevention measures in summer between traffic control workers and construction workers in Japan. Ind Health 45(1):91-99

International Organization for Standardization (2004) ISO 7933:2004, Ergonomics of the thermal environment-analytical determination and interpretation of heat stress using calculation of the predicted heat strain. Geneva, Switzerland.

International Organization for Standardization (2017) 7243 Ergonomics of the thermal environment-assessment of heat stress using the WBGT (Wet Bulb Globe Temperature) Index (ISO
7243: 2017). In International Organization for Standardization: Geneva, Switzerland

Khashei-Siuki A, Sharifan H (2020) Comparison of AHP and FAHP methods in determining suitable areas for drinking water harvesting in Birjand aquifer Iran. Groundwater Sustain Dev 10:100328

Kjellstrom T, Briggs D, Freyberg C, Lemke B, Otto M, Hyatt O (2016) Heat, human performance, and occupational health: a key issue for the assessment of global climate change impacts. Annu Rev Public Health 37:97-112

Lee H-C, Chang C-T (2018) Comparative analysis of MCDM methods for ranking renewable energy sources in Taiwan. Renew Sustain Energy Rev 92:883-896

Li RYM, Wing CK, Zeng F (2019) Ranking of risks for the existing and new building works. Sustainability 11:2863. https://doi.org/ $10.3390 /$ su 11102863

Liu H-C, Liu L, Liu N, Mao L-X (2012) Risk evaluation in failure mode and effects analysis with extended VIKOR method under fuzzy environment. Expert Syst Appl 39(17):12926-12934. https://doi.org/10.1016/j.eswa.2012.05.031

Lyu H-M, Zhou W-H, Shen S-L, Zhou A-N (2020) Inundation risk assessment of metro system using AHP and TFN-AHP in Shenzhen. Sustain Cities Soc 56:102103

Martínez-Solanas È, López-Ruiz M, Wellenius GA, Gasparrini A, Sunyer J, Benavides FG, Basagaña X (2018) Evaluation of the impact of ambient temperatures on occupational injuries in Spain. Environ Health Perspect 126(6):067002

Nasseri, H. (2008). Fuzzy numbers: positive and nonnegative. Paper presented at the International Mathematical Forum.

Omidvar M, Mazloumi A, Mohammad Fam I, Nirumand F (2017) Development of a framework for resilience measurement: Suggestion of fuzzy Resilience Grade (RG) and fuzzy Resilience Early Warning Grade (REWG). Work 56(3):463-474

Omidvar M, Nirumand F (2017) An extended VIKOR method based on entropy measure for the failure modes risk assessment-A case study of the geothermal power plant (GPP). Saf Sci 92:160-172

Opricovic S, Tzeng GH (2007) Extended VIKOR method in comparison with outranking methods. Eur J Res 178(2):514-529

Opricovic S, Tzeng G-H (2004) Compromise solution by MCDM methods: A comparative analysis of VIKOR and TOPSIS. Eur $\mathbf{J}$ Oper Res 156(2):445-455

Parsons K (2019) Human heat stress. CRC Press

Prevention CFDC (2008) Heat-related deaths among crop workersUnited States, 1992-2006. MMWR Morbidity and Mortality Weekly Report 57(24):649-653

Saaty TL (2008) Decision making with the analytic hierarchy process. Int J Serv Sci 1(1):83-98

Samaniego-Rascón D, da Silva MCG, Ferreira AD, Cabanillas-Lopez RE (2019) Solar energy industry workers under climate change: a risk assessment of the level of heat stress experienced by a worker based on measured data. Saf Sci 118:33-47

Shemshadi A, Shirazi H, Toreihi M, Tarokh MJ (2011) A fuzzy VIKOR method for supplier selection based on entropy measure for objective weighting. Expert Syst Appl 38(10):12160-12167

Spector JT, Masuda YJ, Wolff NH, Calkins M, Seixas N (2019) Heat exposure and occupational injuries: review of the literature and implications. Curr Environ Health Rep 6(4):286-296

Swaen GMH, Van Amelsvoort LGPM, Bültmann U, Kant IJ (2003)0 Fatigue as a risk factor for being injured in an occupational accident: results from the Maastricht Cohort Study. Occupat Environ Med 60 (Suppl 1), i88-i92. https://doi.org/10.1136/oem. 60.suppl_1.i88

Wang F, Kuklane K, Gao C, Holmér I (2010) Can the PHS model (ISO7933) predict reasonable thermophysiological responses while wearing protective clothing in hot environments? Physiol 
Meas 32(2):239-249. https://doi.org/10.1088/0967-3334/32/2/ 007

Zadeh LA (1965) Fuzzy sets. Inf Control 8(3):338-353

Zhang S, Zhu N, Lv S (2021) Human response and productivity in hot environments with directed thermal radiation. Build Environ 187:107408. https://doi.org/10.1016/j.buildenv.2020.107408

Zheng G, Zhu N, Tian Z, Chen Y, Sun B (2012) Application of a trapezoidal fuzzy AHP method for work safety evaluation and early warning rating of hot and humid environments. Saf Sci 50(2):228-239. https://doi.org/10.1016/j.ssci.2011.08.042

Publisher's Note Springer Nature remains neutral with regard to jurisdictional claims in published maps and institutional affiliations. 